paralytischen Mundspeichelabsonderung vollständig klar ersichtlich ist. Sollte die Menge der Bauchspeichelabsonderung als Einwand gegen die vorausgesetzte Analogie mit dem Mundspeichel gelten, so besitzt man doch Angaben über enorme paralytische Mundspeichelmengen. $\mathrm{Ob}$ eine solche Analogie zwischen Bauch- und Mundspeicheldrüsen wirklich stattfinde, würde möglicherweise durch Atropinisirung während beiderlei paralytischer Absonderung zu entscheiden sein. -

Zum Schluss ist es uns eine angenehme Pflicht, dem Herrn Prof. Dr. E. Cy on unseren innigen Dank auszusprechen, für die Rathschläge, mit denen er auf die liebenswürdigste Weise uns bei der Ausfïhbrung unserer Untersuchungen in seinem ehemaligen Laboratorium an der hiesigen medicinisch-chirurgischen Akademie stets unterstitzt hat.

(Physiologisches Laboratorium des Herrn Prof. Goltz in Strassburg i. E.)

Aus einem Briefe an den Herausgeber.

\title{
Ein Vorlesungsversuch mittelst des Fernsprechers
} (Telephons).

Von

\section{Prof. Fr. G oltz.}

Der Fernsprecher, dessen Beschreibung jetzt die Runde durch alle öffentlichen Blätter gemacht hat, lässt sich auch zu physiologischen Versuchen verwerthen. Sobald ich Näheres über die Zusammensetzung dieser Vorrichtung erfahren hatte, fiel mir ein, ob die Induktionsströme, welche in derselben wirksam sind, geeignet sein möchten, Nerven und Muskeln zu reizen. Nachdem ich mir daher einen Fernsprecher verschafft hatte, habe ich mit Unterstützung des Herrn Dr. Gaule die nöthigen Versuche angestellt und meine Erwartungen bestätigt gefunden. Heute haben wir diese Versuche mit bestem Erfolge in meiner Vorlesung wiederholt. 
Schaltet man in die Leitung des Fernsprechers zwei nadelförmige Elektroden, ïber welche man den Nerv eines stromprüfenden Froschschenkels brïckt, so zucken die Muskeln des Präparats, sobald ein kräftiger Schall die Membran des Apparats in Bewegung versetzt. Ruft man die Selbstlauter gegen die Membran hin, so zucken die Muskeln sebr kräftig, wenn a, o oder $\mathfrak{u}$ angegeben werden, dagegen weniger kräftig, wenn e oder $\mathrm{i}$ in derselben Tonhöhe and Stärke erklingen. Spricht man die deutsehen Zahlwörter eins, zwei, drei u. s. w., so zuckt das Präparat nach jedem Wort, doch mit ungleicher Stärke. Am schwächsten ist die Zuckung nach dem Zahlwort "sieben" oder fällt wohl ganz aus. Auch nach dem Ruf „vier" ist die Zuckung nur schwach, während die übrigen Zahlwörter mit mehr oder weniger kräftigen Bewegungen beantwortet werden.

Fügt man die primäre Rolle eines $\mathrm{Du}$ Bois'schen Schlittens in die Leitung des Fernsprechens ein, so sind die Ströme, welche dann in der sekundären Rolle inducirt werden, ebenfalls geeignet, um Muskelnerven des Frosches zu reizen. Man kann sogar die sekundäre Rolle bei dieser Anordnung so weit verschieben, dass nur noch der Rand der sekundären Rolle gerade den Rand der primären Rolle ïberdeckt, und doch sind die Ströme in der sekundären Rolle noch wirksam genug, Tetanus auszulösen, wenn man einen Schall erzengt. $\mathrm{Zu}$ allen diesen Versuchen genügt die Anwendung einer einzigen Röhre des Fernsprechers. (Der vollständige Apparat besteht bekanntlich aus zwei durch die Leitung verbundenen einander völlig gleichen Röhren.) Die Ströme, welche, wie mitgetheilt, Muskelnerven so leicht in Tetanus versetzen, verursachen durch die Spitze der menschlichen Zunge geleitet keine Empfindung. Es gelang uns auch nicht mittelst des Fernsprechers den Vagus des Frosches so weit zu erregen, dass eine Aenderung der Schlagfolge des Herzens bemerkbar gewesen wäre. - Eine Hälfte des Bell'schen Ferasprechers, wie ich ihn benutzt habe, kostet hier 6 Mark, und ist also die Anschaffung zu Vorlesungsversuchen wohl zu empfehlen. 